\title{
Do Discurso Sobre a Justiça
}

\author{
Tércio Sampaio Ferraz Jr. \\ Profdssor Titular de Filosofia e Teoria Geral \\ do Direito da Faculdade de Direito da Univer- \\ sidade de São Paulo.
}

\section{Introdução}

O conceito de justiça é, talvez, o mais disputado na literatura jusfilosófica de todos os tempos. Concentra, desde os primórdios do pensamento, as mais acesas controvérsias jurídicas. Definí-lo é uma empresa inesgotável, mas sempre renovada. Em diferentes planos, ora lançada nas dimensões ideais de um alvo ético a perseguir, ora imiscuída na própria existência como uma tarefa constantemente realizada, ora apontada como um dado lógico da axiomática jurídica, a noção de justiça é um tema do qual, dogmática, crítica ou ceticamente, não se pode fugir.

Não é nosso objetivo, neste trabalho, propor mais uma conceituação que venha acrescer a literatura jurídica inutilmente, nem realizar um levantamento histórico da sua diversidade conceitual. Partindo do fato de que a justiça está sempre presente no espírito humano, o que a torna um tema irrecusável do pensamento, nosso plano é investigar não só os fundamentos deste fato, mas sobretudo as suas implicações para o discurso sobre a justiça. Para que, entretanto, esta investigação não se torne uma empresa demasiadamente abstrata, vamos partir de alguns dados concretos da cultura ocidental, tomados, é verdade, numa generalidade às vezes perigosa e simplificadora, mas sempre capazes de delimitar ou circunscrever metodologicamente as nossas ambições.

\section{Justiça e Relativismo}

Por certo, a dificuldade primeira com que depara aquele que pretende versar o tema da justiça é o problema da relatividade da sua conceituação. Esta dificuldade revela-nos a mais antiga tradição sofista. "Pois que tais coisas parecem justas e belas a cada cidade, são-nos também para ela, enquanto 
as creia tais", nos diz Protágoras pela pena de Platão (Teeteto, 167): Nesta mesma época, entretanto, já se desenvolvia a idéia da existência de um critério imutável, universal e absoluto, que se aplica às relações entre os homens. Esta oposição e disputa de 2.500 anos, que ainda não se resolveu, apresenta, no decurso da nossa história, um movimento sinuoso que bem configura o quadro controvertido das noções de justiça que conhecemos.

Há, nos inquéritos sobre a justiça, conforme nos faz ver ARNold Brecht (Teoria Politica, trad. bras. 1965, Rio de Janeiro, v. 1, p. 197 ss.), um duplo caráter da relatividade. Existem dois níveis distintos em nossas idéias de justiça. "Ou nosso pensamento se move, rigorosamente, dentro das instituições de nosso atual estado de civilização, a que se pode chamar a idéia (sentimento, sentido) "tradicional" de justiça; ou pode transcender as instituições tradicionais, caso em que podemos falar de uma idéia (sentimento, sentido) "transtradicional" de justiça" (p. 198).

A idéia "tradicional" de justiça assenta-se nas instituições fundamentais, que constituem a base da vida social cotidiana. A justiça é aí relativa a um determinado estado de coisas. BRECHT denomina esta relatividade de "primeira potência". A idéia de justiça parece aqui exprimir uma ânsia de "a-justamento" a um estado de coisas aceito. No mundo ocidental, este estado de coisas se funda em alguns pilares básicos como a monogamia, a família, a propriedade privada, a herança, o contrato. A partir deles, aceitamos, consciente ou inconscientemente, um padrão determinado de justiça, usamo-lo como base para posteriores ilações, extraindo dele, mais ou menos amplamente, todas as possíveis implicações, aceitamos leis e regulamentos, que conduzem a situações de conveniência e certeza, argumentamos contra "abusos". Em outras palavras, à idéia "tradicional" de justiça é relativa a algo "objetivo", às instituições vigentes.

A idéia "transtradicional" revela uma atitude crítica, na medida em que um "estado de coisas" só será preferido em função de um outro critério, que lhe é exterior. Temos aqui uma "relatividade de segunda potência", pois o padrão escolhido deixa de se relacionar só com fatores "objetivos", para referir-se a uma convicção ou credo "subjetivo". Estes são múltiplos e variados. Esquematizá-los e ordená-los seria uma tarefa incoerente. Sua delimitação seria já, de per si, estabelecer limites absolutos e negar a própria relatividade que lhes é imanente. 
Evidentemente, idéia "tradicional" e "transtradicional" separam-se por uma intenção metodológica, estando, a nosso ver, na realidade, intimamente unidas, em relação de mútua dependência; toda idéia "tradicional" aponta para uma "transtradicional"; toda idéia "transtradicional" vale para uma "tradicional", estabelecendo-se entre ambas uma relação dialética não de anulação, mas de "implicação-polaridade", no sentido que esta expressão toma na doutrina de MIGUEL REALE (cf. Filosofia do Direito, São Paulo).

Esta relação dialética, parece-nos, traduz um esforço constante e inesgotável para estabelecer valores éticos absolutos e uma ordenação absoluta entre eles, esforço que nos conduz sempre a um impasse. Não é, neste sentido, nossa intenção fazer um inquérito sobre os valores em geral nem, pelo menos, sobre os valores éticos, porque sairíamos do âmbito desta investigação, não se podendo prever se chegaríamos a resultados suficientemente concretos para edificar uma teoria dos valores. Por outro lado, devemos precaver-nos da falácia que nos faria crer ser toda e qualquer investigação sobre este tema uma completa impossibilidade, na medida em que o conceito de justiça depende enormente de fatores, cuja universalidade é sempre discutível. Há, nestes termos, um certo número de indicações de que todas as idéias de justiça, todas as variedades de pensamento respeitantes a ela possuem algo em comum. Referímo-nos - embora consciente da extrema generalidade e abstratidade deste dado - ao fato de que o termo justiça ou o seu equivalente aproximado existe em toda parte, de que o anseio humano de justiça é um fator tão universal que ninguém, na vida pública ou privada, pode negligenciar a apresentação de seus atos como justos (ou injustos).

\section{Tipos de discurso: monólogo e diálogo.}

Partimos desta base: justiça é um tema irrecusável. A relatividade da sua conceituação é, entretanto, um dado intransponível. Isto não significa, porém, que toda e qualquer conceituação seja boa, nem que todas devam ser aceitas simultaneamente, sem discussão.

"Eu afirmo que a Verdade é tal como escrevi: cada um de nós é a medida das coisas que são e das que não são, de mil modos entretanto um do outro diferindo por isto mesmo que, para um, umas coisas são e parecem, mas outras, para outro" (Teeteto, 166d). Com estas palavras postas por Platão na boca de Protágoras, cremos estar colocando, embora em 
outra formulação, o mesmo problema acima proposto. A sofística descobriu desde o princípio a dificuldade de se estabelecer uma linha divisória entre alétheia e doxa, reduzindo tudo à segunda e proclamando a divergência insuperável das opiniões. Mas descobriu também que os homens se deixam persuadir com freqüência pelo discurso e que é sempre possível opor persuasivamente a um argumento um argumento contrário ou tornar mais forte a razão mais fraca. Assim, se o discurso, de um lado, deixa de ser um instrumento de informação, não tendo qualquer sentido epistemológico, ele facilita, por outro, a coexistência humana: tem sentido ético.

ARISTóTELES, retomando a questão, não sem criticar profundamente o pensamento sofístico, procura restabelecer a distinção entre alétheia e doxa, ressalvando, assim, a possibilidade do sentido epistemológico do discurso, sem olvidar-lhe o sentido ético.

O conhecimento epistêmico (científico, verdadeiro) é atribuível, segundo o filósofo, ao conhecimento universal. A sensação coloca-nos diante daquilo que depende das condições espácio-temporalmente inconstantes. Enquanto o universal não é aí determinado, o objeto sensível permanece incerto (A. Post. II, 19.100 a 15). O particular, na sensação, é sempre ilimitado, isto é, indeterminado. Deste modo, o progresso necessário que vai do ilimitado ao limitado mostra-se como a condição constitutiva da ciência. O universal, entretanto, não é como que uma soma ou resumo dos dados da experiência, mas um "limite" (péras), em cuja estabilidade ou determinabilidade repousa a estabilidade da própria experiência (episteme relacionada a stênai). O universal (kathólou), porém, se diferencia não apenas do particular (kath' hékaston), mas também do genérico (koinón) (An. Post. I, 11, 77 a 26-31). Pois a generalidade é também uma espécie de indeterminabilidade (ápeiron), e, neste sentido, objeto de um pensamento tópico (ARISTÓTELES diz "dialético") e não de um científico ou apodítico, estando a ciência, assim, num ponto intermediário entre a particularidade e a generalidade.

Esta diferença entre pensamento apodítico e dialético implica, segundo nos parece, a oposição acentuada por THEODOR VIEHWEG entre scientia e prudentia, entre pensamento sistemático e problemático (cf. Topik und Jurisprudenz, München, 1965). A "tópica", como denomina ele o pensamento prudencial, é uma técnica de pensar sobre os problemas, que se desenvolveu no seio da retórica, cuja tradição remonta à sofística e a ARISTótETES. Este estabelecia a seguinte 
classificação: temos uma apodítica, quando a conclusão se obtém partindo de proposições universais, verdadeiras e primárias ou delas derivadas; uma conclusão dialética é a que se extrai de opiniões; uma conclusão erística ou sofística é a que se baseia sobre meras aparências de opiniões que não o são efetivamente; finalmente, temos as conclusões errôneas, equivocadas ou deficientes, baseadas em proposiçōes particulares de determinadas ciências. Esta classificação permite não apenas garantir o conhecimento científico ou universal, mas também restaurar o valor da opinião, livrando-a da mera arbitrariedade.

Viehweg fala-nos, neste sentido, de pensamento aporético ou de aporias. A palavra aporia expressa a "ausência ou carência de caminho". A tópica, enquanto pensamento aporético, é, assim, pensamento problemático. Fundado em Nicolar HartmanN, opõe ele, problema à sistema. Problema, define, é toda questão que, aparentemente, permite mais de uma resposta, e que pressupõe, necessariamente, uma compreensão preliminar e provisória, em virtude da qual algo aparece como uma questão que deve ser levada a sério, para a qual se procura uma solução. Sendo um sistema uma conexão de derivações, deve-se, então, dizer, que o problema se insere num sistema, com o fito de se encontrar sua solução (p. 16). Ora, o modo de pensar sistemático parte da totalidade. Nele, a concepção é o primeiro e segue sendo o predominante. Do ponto de vista do sistema, os problemas são selecionados: os que são incompatíveis com o seu ponto de vista são rechaçados e agrupados como problemas mal colocados ou falsos problemas. $\mathrm{O}$ modo de pensar aporético comporta-se inversamente. Não se duvida de que haja um sistema nem de que, eventualmente, em seu próprio pensamento, este sistema esteja em forma latente e seja o determinante, mas não chega a conhecer ou captar este sistema. Assim, do ponto de vista do problema, os sistemas são selecionados, conduzindo-nos, em geral, a uma pluralidade deles, sem submete-los a nenhum sistema superior (p. 17).

À primeira vista, percebe-se uma insegurança neste procedimento, onde, aparentemente, a skepsis sofista desponta. É possível, entretanto, distinguir não só entre a maior ou menor força de uma argumentação problemática, como também se busca, sempre, um apoio que, de modo fácil, se acha em um repertório de pontos de vista já preparados ou dados. Assim surgem os catálogos de tópicos. O procedimento que se utiliza de tais catálogos denomina Viehweg "tópica de segundo grau" (p. 18). 
A tópica, enquanto pensamento aporético, visa a assinalar sugestões, a apontar possibilidades, a desvendar caminhos que nos livrem da situação insolúvel. O pensamento tópico, é, pois, por excelência, destinado a decidir ou preparar uma ação. Seu campo não é propriamente o da objetividade. A objetividade, conforme nos mostra Perelman (Traité de l'Argumentation, Paris, 1958), pertence à ciência, ao pensamento demonstrativo e significa a relação unívoca entre uma proposição significante e o seu significado (quanto ao mesmo problema em relação à ciência política, cf. CELSO LAFER: "The planning process and the political system in Brazil" - Cornell University, 1970 , p. 280 ss.). O que se pede, no campo tópico, é a "imparcialidade", que é, por princípio, uma noção relativa; pois a "imparcialidade" se dá, sempre, aqui e agora, ela resulta do embate das opiniões, dentro de uma comunidade determinada. P.or isso mesmo, deve-se distinguir entre os aspectos do raciocínio humano que se ligam à verdade e os que se referem à adesão. O que caracteriza esta última é a dimensão variável de sua intensidade. $\mathrm{Na}$ evidência científica, numa demonstração matemática, não há graus de verdade: ou aceitamos ou recusamos o raciocínio. No pensamento tópico, entretanto, justamente porque não se trata da verdade, mas da verossimilhança, pode-se falar em graus de intensidade de adesão a uma argumentação qualquer.

A tópica moderna funda-se, sem dúvida, na tópica antiga, ampliando-lhe alguns aspectos, restringindo outros. 0 mais importante deles, que se conserva, é a idéia de auditório. 0 discurso tópico só tem sentido para um auditório determinado. A palavra auditório tem, evidentemente, um sentido amplo. Também o texto escrito tem o seu "auditório". O importante aqui é ressaltar o caráter dialógico do pensamento tópico. Este implica o estabelecimento de quadros (tópoi) que sirvam de pontos de referência. Implica ademais que os participantes da argumentação ou os seus destinatários se achem dispostos a ser convencidos. Implica também que há alguma coisa que tem de ser discutida. Implica igualmente que quem desenvolve a argumentação tem de levar em consideração as reações dos que escutam. Em suma, o pensamento tópico é um diálogo, uma discussão. Ao contrário, o pensamento apodítico constitui um monólogo.

O discurso monológico caracteriza-se, a nosso ver e sem a pretensão de uma análise exaustiva, em primeiro lugar, pela indiscutibilidade. Evidentemente todo discurso se dá numa situação comunicativa. Não há discurso sem orador, mas 
também não há discurso sem ouvinte (cf. KUNO LORENZ: Elemente der Sprachkritik, FrankfurtkM. 1970). A estes dois elementos acrescente-se um terceiro: 0 objeto do discurso (ARISTóteles: Retórica: I, 3, 1358 a 36). O ouvinte é visado pelo orador ou como participante de uma decisão ou como observador passivo. Esta duplicidade funda-se na qualidade do objeto do discurso, que pode ser: ou um dubium, caso em que o ouvinte entra em relação com o orador como parte que deve ser conquistada pela argumentação, tendo em vista um eventual ajustamento das opiniões; ou um certum, caso em que o papel do ouvinte é radical: ou se submete e aceita ou se insurge e recusa.

No discurso monológico, o ouvinte está presente, mas aparece como não habilitado para uma decisão e, em conseqüência, não ativamente interessado nela: ele se põe em face do objeto do discurso (certum) com reservada distância. Para ele, o objeto da eventual deliberação não é o objeto do discurso, mas o próprio discurso. Assim o discurso monológico abstrai o ouvinte, perdendo, de certa forma, a dimensão pragmática. Mas, por outro lado, abstrai também o orador, que se torna apenas um instrumento. O discurso monológico, deste modo, torna-se (ao menos na aparência, isto é, se não submetido a uma análise profunda) subsistente por si e em si. $\mathrm{E}$ de modo radical: subsistente ou nada. Daí, provavelmente, a aparência de atemporalidade e a espacialidade do discurso científico, conforme os padrões das chamadas ciências naturais e exatas. É claro que o discurso científico não é apenas monológico, mas fica em aberto a possibilidade de uma divisão das ciências conforme o grau de monologicidade que possa caracterizar o seu discurso.

Num sentido estrito, portanto, não há em geral um verdadeiro diálogo entre os cientistas: há polêmicas - contra a evidência não se argumenta. $\mathrm{O}$ discurso monológico não desenvolve uma argumentação, mas uma demonstração. A demonstração é captada pelo ouvinte como uma exibição (epideixis) - (sobre epideixis enquanto demonstratio, ostentatio cf. HEINRICH LAUSBERG: Handbuch der literarischen Tethorik, 2 vols. Munchen, 1960). Uma exibição que se observa e se admira em si e como tal. Ao contrário, o discurso dialógico é sempre argumentativo.

Em primeiro lugar por causa do objeto do discurso. Como no discurso monológico o objeto é um certum, não cabe nunca o questionamento do próprio objeto, que aparece como um dado. A demonstração fixa-se por isso na definição, isto é, na prova 
de uma correta denominação do objeto, com a aplicação dos diferentes métodos que a lógica da ciência não se cansou de descrever e analizar. Ao contrário, sendo o objeto do discurso dialógico sempre um dubium, o procedimento tem que ser a argumentação, que se expressa pelo modo do questionamento: a questão é a expressão verbal do dubium. Daí, também, o caráter problemático e aporemático do discurso dialógico, a partir do próprio objeto, que pode estar envolvido pela dúvida já no que tange à sua existência mesma.

No discurso dialógico, portanto, o objeto é sempre discutível, é sempre um dubium, embora na intenção do discurso (dimensão pragmática) possa haver sempre a tentativa de um certum. Isto, aliás, diferencia basicamente o discurso dialógico tópico do sofístico, onde o dubium nunca se transformará em provável.

O discurso dialógico, enquanto tópico, não abstrai, pois, nem o orador, cuja intencionalidade (no sentido pragmático) está sempre presente, nem o ouvinte, que é convidado a participar da decisão sobre o objeto do discurso e sobre a sua formulação (res et verba). Observe-se, neste sentido, que o objeto do discurso, o dubium, pode ser tanto o objeto que não tenha sido, a princípio, intencionado por ele. Nestes termos, na relação estabelecida entre orador e ouvinte, ambos são admitidos como aptos para a discussão. Por isso, o discurso dialógico nunca impõe nem exige qualquer submissão. Ele só subsiste enquanto as partes se aceitam mutuamente. Ele nunca é evidente, quando muito é persuasório.

No que se refere à participação do ouvinte, ARISTóteles (Ret. loc. cit.) distingue dois casos, tendo em vista a situação temporal do objeto do discurso: se este pertence ao passado, o ouvinte é chamado a participar como juiz; se pertence ao futuro, o ouvinte aparece como legislador. Daí os gêneros básicos: judicação e deliberação. A judicação é, fundamentalmente, dialógica. A deliberação o é menos. A demonstração é, fundamentalmente, monológica.

Tendo em vista a distinção entre monólogo e diálogo, podemos anotar alguns exemplos que nos parecem elucidativos. Assim, diríamos que os discursos platônicos são diálogos com seus discípulos, monólogos em relação a Heráclito. Assim, o discurso da Igreja na sociedade medieval pode ser considerado dialógico. Ele deixa de sê-lo a partir do momento em que a fé não é mais algo a que se adere, para ser algo a que se submete (ou que se impugna). Isto é, no momento em que a fé tem de ser imposta, o discurso passa a ser monológico. Sob 
este ângulo poder-se-ia ver ainda a distinção rousseauniana entre a vontade geral e a vontade de todos. A vontade geral é a que existe no conjunto dos cidadãos, dos homens que renunciarem a todos os seus direitos em favor deste conjunto constituído por eles mesmos, depois do Contrato. A vontade de todos, em oposição, é a soma das vontades particulares. A primeira visa ao interesse comum; a segunda, ao privado. Pois bem: a sociedade onde impera a vontade de todos é uma sociedade do monólogo; aquela onde predomina a vontade geral é a do diálogo.

\section{Justiça: tema privilegiado do discurso dialógico}

A justiça é tipicamente um dubium. O discurso sobre a justiça é, pois, eminentemente dialógico. Assim já o determinara ARIsTóteles. Para ele, a justiça, enquanto forma do mundo político, não é, como entenderia KANT, sua condição de possibilidade, mas sua atualização. Não é um dado externo, mas imanente. Não é um dado separado de uma realidade caótica. A forma abstraída da matéria não é para ARISTóteles, um dado do ser. Enquanto componentes reais do ser, matéria e forma não são como partes do ser. A prova está em que não podem ser dissociadas fisicamente: não é possível conceber um ser fisicamente existente só de matéria, sem forma (Met. $\Delta, 3,1014$ a 26 ; Fis. II, 2,194 b 19). O mundo político há de ser necessariamente um mundo "informado" de justiça, sob a pena de deixar de ser o que é. A justiça é forma. A forma é aquilo que nós vemos da coisa, o que nela há de mais manifesto. Por outro lado, é também o que há de mais obscuro, mais aporético, na essência. Isto significa que a forma é o que se deixa manifestar mais claramente no discurso, isto é, é simples descrevê-la; mas é e permanece obscura sua relação com a matéria. Por isso, diz ARIstóteles, a forma é o tema privilegiado do discurso dialético (tópico, dialógico) sendo a definição dialética, por oposição à verdadeira definição física, a que se atém à forma e renúncia ao conhecimento de que matéria esta forma é forma. Esta é a razão pela qual, se é claro para ARISTóteles que a justiça é uma igualdade proporcional, a relação disto com a realidade permanece extremamente obscura. Por isso mesmo todo o capítulo $\mathrm{v}$ da Ética Nicomaquéia é um texto que se estrutura no descobrimento e manipulação das premissas, na diferenciação das diversas determinações categoriais e no esclarecimento da equivocidade 
das expressões da língua, no descobrimento das diferenças de gênero e espécie, no descobrimento das semelhanças entre os diversos gêneros, segundo o procedimento descrito nos Tópicos, I, 13-18.

Não faltam, na história do pensamento, exemplos de filósofos e juristas que tentaram dar à justiça um tratamento monológico. Entretanto, a própria natureza do objeto lhes destruiu sempre a pretensão. A justiça não é objeto de um discurso monológico. Não é um certum. É um dubium. Sob o ponto de vista exclusivo do ato humano, este será qualificado como justo, se se adequa à aplicação correta de uma regra. Todos aqueles aos quais se aplica a mesma regra devem ser tratados da mesma maneira, sejam quais forem as conseqüências. A regra é a igualdade. De todos os postulados da justiça, talvez o mais universal deles, mas também o mais abstrato e formal, é o da igualdade. A exigência de igualdade é um dos mais antigos princípios da convivência. Estampada já na famosa lei de Talião, ela recebe com ARISTótELES uma formulação decisiva. A noção de justiça como igualdade proporcional, que se realiza na forma da proporção aritmética e geométrica, representa a esquematização de uma idéia central que orienta e informa, até hoje, o pensamento jurídico da cultura ocidental (cf. nosso trabalho $L a$ noción aristotélica de justicia in “Atlantida, v. vII n. ${ }^{\circ}$ 38, Madrí, março-abril de 1969, p. 166 ss.).

A igualdade perante a lei é uma peça fundamental no jogo político, postulado elementar nas mais diversas formas de democracia. Pois bem: qual é a razão que nos conduz a pensar na igualdade sempre que levantamos um problema de justiça? Esta é a pergunta colocada pelo jurista EDMOND N. CAHN em seu livro The sense of injustice (New York, 1949, p. 24). Curiosamente nos fala ele de um "sentimento de injustiça" e não de "justiça". Na sua opinião, o "sentimento de injustiça" não é apenas condição de possibilidade de qualquer ordenamento jurídico, pois a mera pressuposição lógica não pode explicar a razão pela qual nos insurgimos às vezes tão violentamente contra um tratamento desigual para partes iguais. Mais do que um pressuposto teorético, temos aí algo enraizado na própria natureza humana, uma espécie de reação resultante de indignação, de intimidamente, de choque, de ressentimento e de fúria, uma reação de natureza fisiológica. Para CAHN, o "sentimento de injustiça" aparece, pois, como uma mistura de racionalidade e emotividade. A 
natureza humana é, assim, de tal modo construída, que diante de qualquer injustiça que fira alguém, o ser humano é capaz de senti-la como diretamente endereçada a si mesmo, provocando-lhe um desejo incontido de restabelecer uma situação de equivalência.

MAX Scheler, diante da mesma questão, afirma ser a moderna teoria da igualdade o resultado explícito do "ressentimento". Por de trás dela vê ele o desejo de espezinhar, de rebaixar aquele que está em posição superior (Das Ressentiment im Aufbau der Moralen, Ges. Werk, Bd. 3, p. 121) : "a exigência de igualdade é sempre uma especulação à baisse".

Bem fundamentada e bastante significativa nos parece, a propósito, a opinião de HELMUT SCHOECK, em seu livro Der Neid, eine Theorie der Gesellschaft (Freiburg - München, 1966, cap. 14). ScHOEcK vai buscar as fontes da justiça, enquanto sentimento de igualdade, na inveja. Em longa argumentação tenta ele mostrar a relação existente entre a inveja e a própria vida social. A seu ver, "ser humano" é, de um lado, em boa parte, equivalente a "ser invejoso", não podendo subsistir nenhuma sociedade que faça depender sua organização da inveja. Por outro lado, a força civilizadora de uma sociedade depende também da sua capacidade de domar, de canalizar a inveja. Nós diríamos, racionalizá-la. É, nestes termos, que a inveja vai aparecer, na sua teoria, com uma função positiva no surgimento do sentimento de justiça enquanto exigência de igualdade.

Em geral, afirma SCHOECK, todo cidadão, na moderna democracia, aceita como pressuposto indiscutível a igualdade perante a lei. Seu direito (subjetivo) à igualdade lhe é assegurado através da inveja de seus concidadãos em relação àqueles que, por meio de um tratamento eventualmente desigual, de algum modo obtenham uma vantagem ou possam obtê-la. Esta igualdade, que se pressupõe sempre respeitada, cria assim um amplo campo de ações para o indivíduo, no qual ele se sente seguro. A inveja, enquanto um órgão vigilante, tem aqui, a seu ver, um efeito positivo, que possibilita mesmo a construção do ser social (p. 255).

A pressão da inveja é, entretanto, tão grande que o homem é conduzido, de várias maneiras, a superá-la ou eliminá-la, vale dizer, racionalizá-la. ScHoEck vê nos movimentos socializantes e o socialismo é um processo racionalizante - uma defesa (utópica) contra os efeitos da inveja, uma 
tentativa de anulá-la. Em sua opinião, porém, o ideal de uma sociedade igualitária está, por princípio, destinado ao fracasso. Pois a inveja é um sentimento que não se anula nunca. Além disso - o que lhe parece mais grave - o igualitarismo elimina, na verdade, qualquer possibilidade de controle sobre a inveja. A sociedade igualitária representa, em primeiro lugar, uma perda da dimensão temporal da justiça: esta deve ser sempre aqui e agora alcançada. Em segundo lugar, a sociedade igualitária destrói a possibilidade de se distinguir entre a "inveja legítima" e a "inveja ilegítima ou vulgar", a que constrói e a que destrói.

A sociedade razoável é aquela capaz de uma atitude franca perante a inveja. Citando Svend RANULF, mostra ele, por exemplo, que a justiça criminal de uma sociedade se funda na inveja latente de todos contra todos, mas de tal modo que, mesmo aquele que nada tenha a ver com um delito qualquer, possibilita a revelação do crime, porque se rebela contra uma vantagem indevida. É o papel do invejoso (inveja legítima ou indignação) como denunciante. Evidentemente, a verdadeira justiça é aquilo que o invejoso nunca é: neutra perante as partes. Mas, de outro lado, ignorar o invejoso ou tentar eliminá-lo torna a vida social (justa) uma impossibilidade.

A teoria de SCHOECK estabelece um fundamento empírico para a tese que nos parece essencial: o conceito de justiça é necessariamente dialógico, não é um objeto dado, mas que se constrói, é uma busca e uma concretização constante. Quando se apresentam razões para duvidar-se de uma lei ou norma, sejam essas razões ministradas pela experiência ou pela consciência, dever-se-á desenvolver uma argumentação para justificar a mudança proposta, para justificar a mudança que pareça mais apropriada para eliminar as inconveniências que hajam surgido. Estes argumentos não são coercitivos, não representam uma necessidade compulsiva, mas podem ser convincentes, persuasórios a um grau satisfatório e constituir uma base razoável para se tomar uma decisão. A justiça é, portanto, um objeto do diálogo, isto é, o discurso sobre a justiça é necessariamente dialógico. Vale dizer: romper o diólogo é romper a possibilidade da justiça.

\section{Uma Palavra Sobre o Direito}

O mundo jurídico é um mundo complexo. Na perspectiva que vimos desenvolvendo, diríamos que qualquer ordem jurídica 
é um mixto de dialogicidade e monologicidade. Isto é, o Direito participa tanto do diálogo quanto do monólogo.

Assim, se todo discurso sobre a justiça é sempre dialógico, o discurso sobre o direito tem, muitas vezes, a estrutura monológica. Todo direito instaura uma ordem e a coloca fora de discussão. E este, sem dúvida, o sentido mais imediato da dogmática jurídica. Sua estrutura é impositiva. A lei, em princípio, impõe e exige obediência: não se pode aceitar parcialmente uma lei ou desejar cumpri-la em parte. De outro lado, porém, não se pode ignorar uma certa flexibilidade em termos de possibilidade de interpretação e discussão do dogma preestabelecido. Em outras palavras, todo jurista sabe muito bem que não há nenhum caso de uma ordem jurídica que não seja imposta. Um sistema de normas, que entra em vigor, é, num primeiro momento, um discurso monológico. Daí a idéia de que todos os seus elementos são claros e conhecidos de antemão, de que o sistema é completo e que, portanto, não admite flexibilidade. Entretanto, uma análise mais percuciente revela a inanidade desta concepção. Ela supõe que a regra, segundo a qual se julga, deve ser clara em todos os campos de aplicação possíveis. Isto significaria, de fato, a monologização total no direito. Mas sucede que a escolha da regra pelo juiz não se acha sempre predeterminada por outras regras da ordem jurídica positiva.

Desde o momento em que, por uma razão ou outra, haja desacordo quanto à aplicação de uma lei, surge o problema da regra justa. Assim sucede quando se tem de encontrar, dentro do conjunto do direito em vigor, a regra precisa, aplicável ao caso concreto. Sucede também quando se trata de suprir o silêncio da lei e de julgar por eqüidade. Ou quando nos opomos à lei positiva, invocando preceitos de outras ordens, regras morais, normas religiosas, direito natural, que são, todos, caracteristicamente, topos do pensamento problemático. Nestes casos, o juiz que atua dentro dos quadros de um sistema jurídico determinado, se preocupa com a ratio juris, com a finalidade da regra particular ou com a finalidade do sistema jurídico em seu conjunto. A função do juiz não se limita, pois à dedução formal : o juiz encarna o direito vivente.

Em conclusão: se o direito tem, no seu momento normativo, uma estrutura monológica, enquanto direito justo, ele é um mixto de monólogo e diálogo. Um sistema jurídico qualquer pode, nestes termos, aproximar-se mais ou menos da estrutura estritamente monológica, embora nunca chegue a instaurá-la 
totalmente. Assim, por exemplo, quando o Estado tenta substituir a juris-prudência pela atividade legislativa, caso comum em muitas ditaduras, onde as dúvidas surgidas na aplicação da lei são subtraídas à apreciação judiciária e resolvidas por uma nova lei, estamos nos aproximando de um modelo monológico, em que a justiça é, conseqüentemente, minimizada.

A monologização total, entretanto, nunca se realiza. Daí uma dupla impossibilidade de reduzir-se o mundo jurídico ao mundo da ciência, do discurso monológico, ou de reduzí-lo, ao contrário, ao mundo do discurso puramente dialógico. 